\title{
Learning from the past and present: social science implications for COVID-19 immunity-based documentation
}

Sara Dada (10 ${ }^{1 凶}$, Heather Battles (10 2 ${ }^{2}$, Caitlin Pilbeam (10 ${ }^{3}$, Bhagteshwar Singh ${ }^{4,5,6}$, Tom Solomon ${ }^{4,7} \&$ Nina Gobat (D) ${ }^{3}$

In responding to the widespread impacts of the COVID-19 pandemic, countries have proposed and implemented documentation policies that confer varying levels of freedoms or restrictions (e.g., ability to travel) based on individuals' infection status or potential immunity. Most discussions around immunity- or infection-based documentation policies have focused on scientific plausibility, economic benefit, and challenges relating to ethics and equity. As COVID-19 vaccines are rolled out, attention has turned to confirmation of immunity and how documentation such as vaccine certificates or immunity passports can be implemented. However, the contextual inequities and local variabilities interacting with COVID-19 related documentation policies hinder a one-size-fits-all approach. In this Comment, we argue that social science perspectives can and should provide additional insight into these issues, through a diverse range of current and historical examples. This would enable policymakers and researchers to better understand and mitigate current and longer-term differential impacts of COVID-19 immunity-based documentation policies in different contexts. Furthermore, social science research methods can uniquely provide feedback to inform adjustments to policy implementation in real-time and help to document how these policy measures are felt differently across communities, populations, and countries, potentially for years to come. This Comment, updated as of 15 August 2021, combines precedents established in historical disease outbreaks and current experiences with COVID-19 immunity-based documentation policies to highlight valuable lessons and an acute need for further social science research which should inform effective and contextappropriate future public health policy and action.

\footnotetext{
${ }^{1}$ UCD Centre for Interdisciplinary Research, Education and Innovation in Health Systems, School of Nursing, Midwifery and Health Systems, University College Dublin, Dublin, Ireland. ${ }^{2}$ University of Auckland, Auckland, New Zealand. ${ }^{3}$ Nuffield Department of Primary Health Care, Oxford University, Oxford, UK. ${ }^{4}$ Institute of Infection, Veterinary \& Ecological Sciences, University of Liverpool, Liverpool, UK. ${ }^{5}$ Christian Medical College, Vellore, Tamil Nadu, India. ${ }^{6}$ Royal Liverpool University Hospital, Liverpool, UK. ${ }^{7}$ NIHR Health Protection Research Unit on Emerging \& Zoonotic Infections, University of Liverpool,

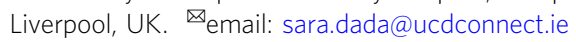




\section{Introduction}

OVID-19 related documentation such as passports, certificates, and licences have been subject to increasing discussion throughout the pandemic (Organization, 2020b). In various contexts, this documentation implies different rights, restrictions, and/or freedoms, based on presumed immunity- or infection-based criteria. Furthermore, these policies have implications at both the domestic and international levels (The Lancet Microbe, 2021). For example, COVID-19 policies implemented early in Denmark and India (and now used by many countries) focus on proving freedom from current infection (Drury, 2020; 2020b), and in El Salvador and Brazil certify an individual's recovery from infection (Phillips, 2020; 2020a). Initially this was to prevent transmission from areas of high burden to those with lower burden of infection; however recently the focus has switched to preventing introduction of new variants of the SARSCoV-2 (Callaway, 2021). As COVID-19 vaccines were rolled out, attention turned to confirmation of immunity. Many of the same questions and concerns are being raised, and the term 'immunity passport' is being applied to potential policies based on vaccination status documentation, such as the European Union's Digital COVID Certificate rolling out in July 2021 (Picard, 2020; 2021c; Gostin et al., 2021). There is therefore a continued need to consider the debates over the last year around 'immunity passports' in the context of vaccination, and what these discussions reveal about the kinds of research and voices needed to better inform policy actions.

Immunity-based documentation is not a new practice in global health governance; today its most recognisable implementation is the yellow fever vaccination certificates required for travel to or from various countries (World Health Organization, 2015). To date, most discussions around immunity-based documentation for COVID-19 have focused on scientific soundness, economic benefit, and ethical challenges of implementation whilst drawing on a narrow selection of historical examples (Persad and Emanuel, 2020; Voo et al., 2020; Phelan, 2020; Voo et al., 2021). Although important contributions, these perspectives miss the real human lives, day-to-day experiences, and 'messy middlegrounds' that underpin them. Here, we argue that discussions around COVID-19 immunity-based documentation should include greater input from humanities and social sciences such as sociology, anthropology, and history to better understand the immediate, short- and long-term impacts of such policies. Through using diverse current and historical examples, we suggest increased attention to the role of context in particular. Greater social science input into health policy decision-making in pandemic preparedness and response adds further richness to understandings of these issues, and the lives and realities with which they are intertwined, and is essential to inform effective health policies and implementation. To this end, we need social science research investigating the impact and experience of immunity-based documentation policies when and where they unfold.

\section{What is immunity, how is it being measured, and what does it mean?}

The approaches being considered for confirming immunity to SARS-CoV-2 focus on different aspects of infection, immunity, and transmission. Options vary regarding what they indicate about the virus and immune response, and therefore have different implications when resulting in a positive or negative test. Table 1 summarises the biomedical and epidemiological rationale and pitfalls of these approaches, refers to parallels from other infectious diseases, and raises potential accessibility and equity implications, which have been the focus of recent debate regarding vaccination. The International Health Regulations, which are drawn up through international consensus for infections such as yellow fever, do not yet govern travel based on vaccination for COVID-19, thus resulting in heterogeneity of approaches between countries (Ferhani and Rushton, 2020; World Health Organization, 2021). For example, there are concerns about lack of coordination and transparency of restrictions to inter-country travel.

The World Health Organization's Director-General has warned world leaders of significant inequity of access to vaccines (World Health Organization, 2021), asking that the COVAX initiative, set up to improve global access to COVID-19 vaccines, not be undermined (Public Health England, 2020). This inequity in vaccine distribution and its implications for vaccination coverage in low and middle-income countries, is further manifested by current COVID-related documentation policies that limit which vaccinations will be accepted by the schemes (Borana, 2021). For example, while India's Serum Institute manufactures the Oxford-AstraZeneca vaccine under a different name, Covishield, it is currently not approved by the European Medicines Agency and therefore not accepted in the EU digital COVID certificate scheme (Borana, 2021). A number of additional COVID-19 vaccines have been produced (for example, in Russia and in China) and more are vying for WHO approval status for emergency use.

The implementation of immunity-based documentation to grant various freedoms to individuals also raises questions about the implications this has for assumed mandatory vaccination and if and how exemptions will be considered. Further, given uncertainty regarding the length of immunity conferred by infection and/or vaccination, protocols for re-issuing immunitybased documentation for the same individual must also be considered. Bringing conversations around vaccination and immunity-based documentation together, the final column in Table 1 suggests related potential priority areas that social science research could help to address, drawing on a crowd-sourced document of medical anthropological research questions (Nichter et al., 2020).

\section{Historical precedents}

As variants of COVID-19 emerge, past experience with other infectious diseases has been one important source of information to guide current action. As multiple commentators highlight, immunity-based documentation policies that allow freedoms to certain populations while restricting others' may result in people seeking infection in order to access these freedoms as well (Phelan, 2020). Such commentaries have frequently pointed to two cautionary historical precedents of intentional infection: yellow fever in the US antebellum South and 'chicken pox parties' in the twentieth century. It is important to consider that whilst intentional infection may be encouraged by policies and documentation requiring proof of infection (e.g., 'immunity' passports), policies and documentation requiring proof of vaccination rather incentivise seeking vaccination (e.g., 'vaccine' passports) (Osama et al., 2021). However, the pursuit of intentional infection may remain a risk in the COVID-19 pandemic where access to vaccines is lacking. While seeking 'natural immunity' may be prioritised as a lifestyle choice in the global north, it may be the only option in many countries around the world with limited vaccine availability. Policymakers must consider how to safeguard against these activities while also balancing the pressure to construct a coherent 'success story' that may skew the apparent cost and benefit of an immunity-based documentation policy (Das, 1999). 


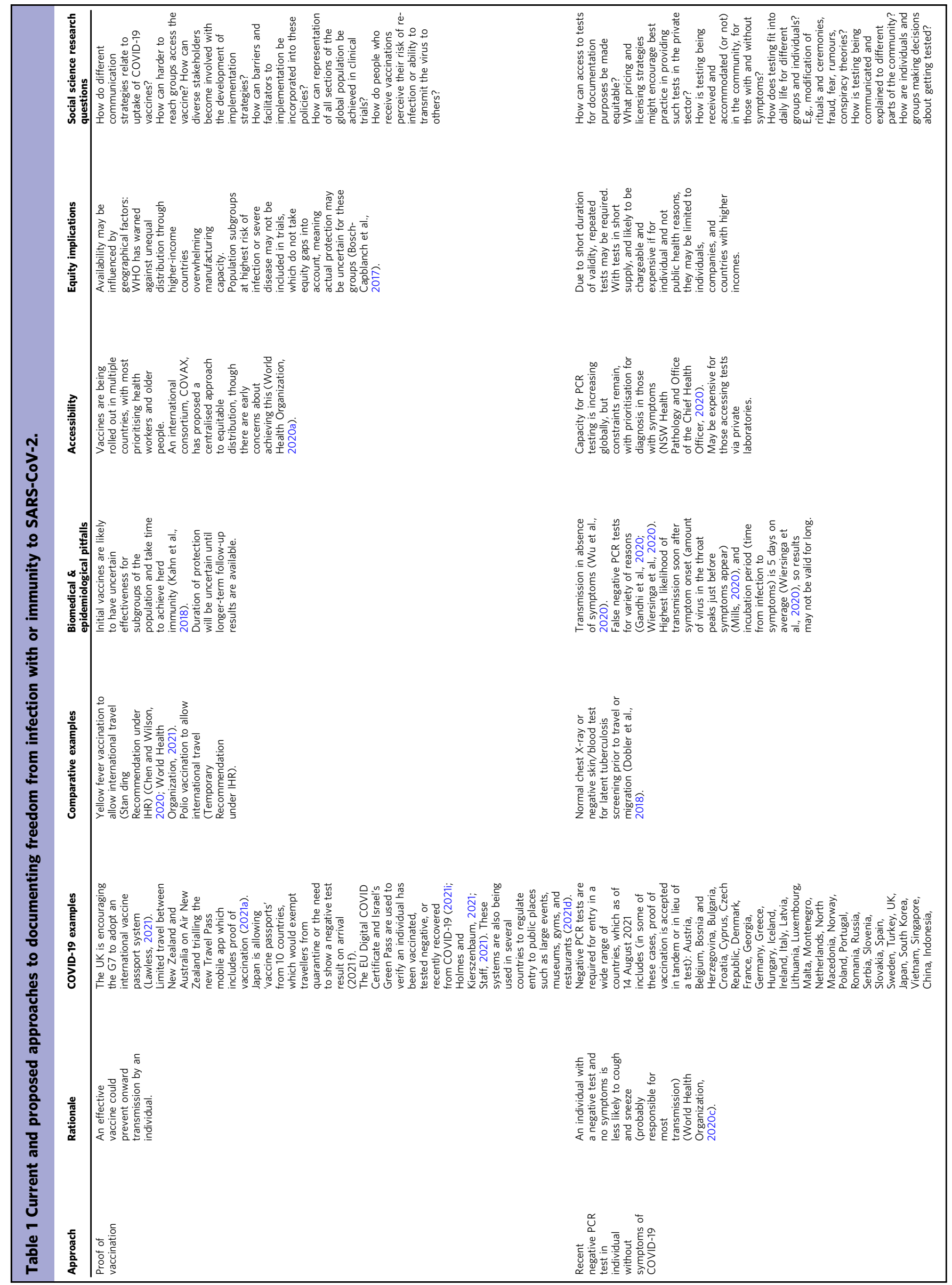




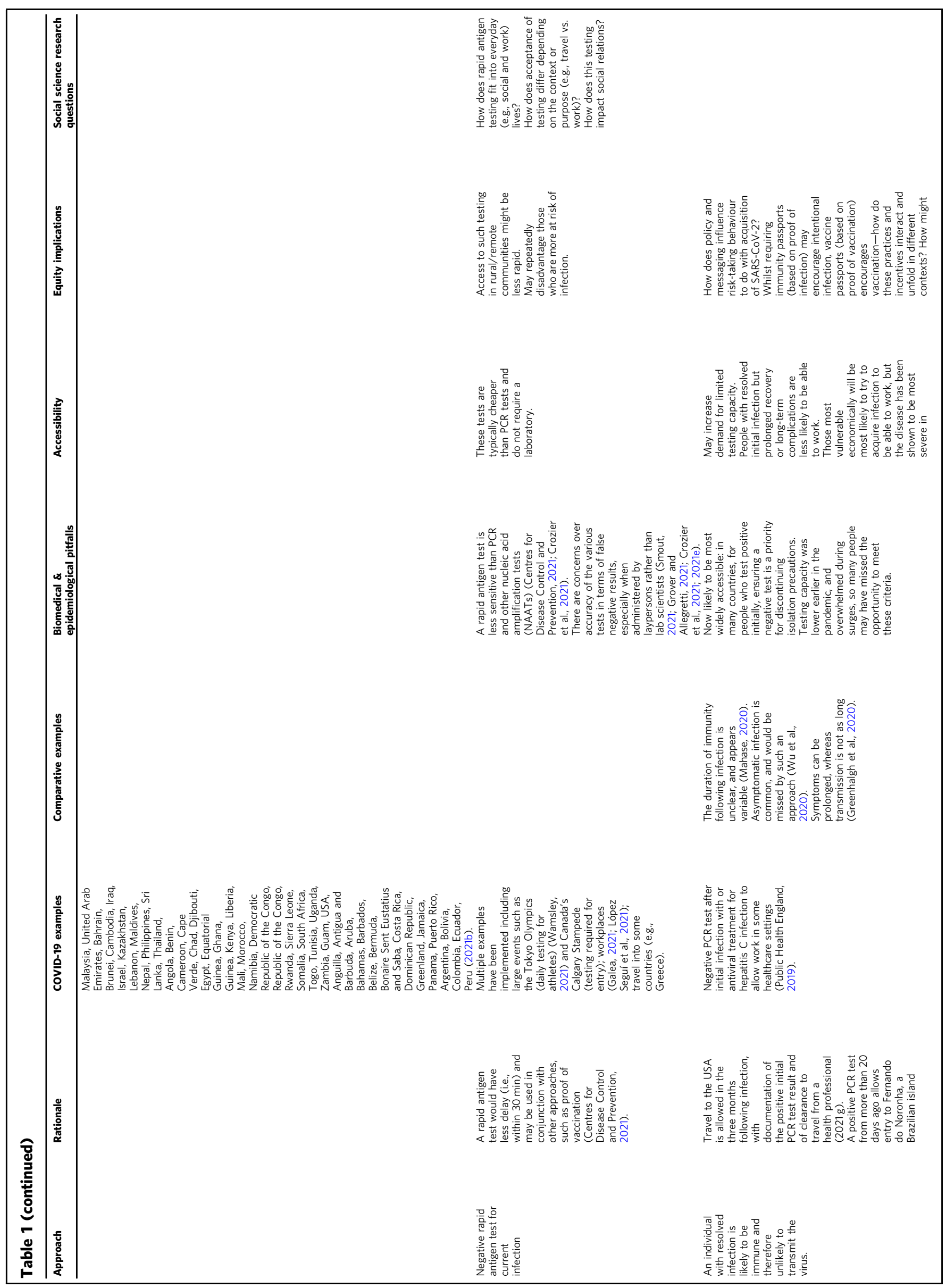




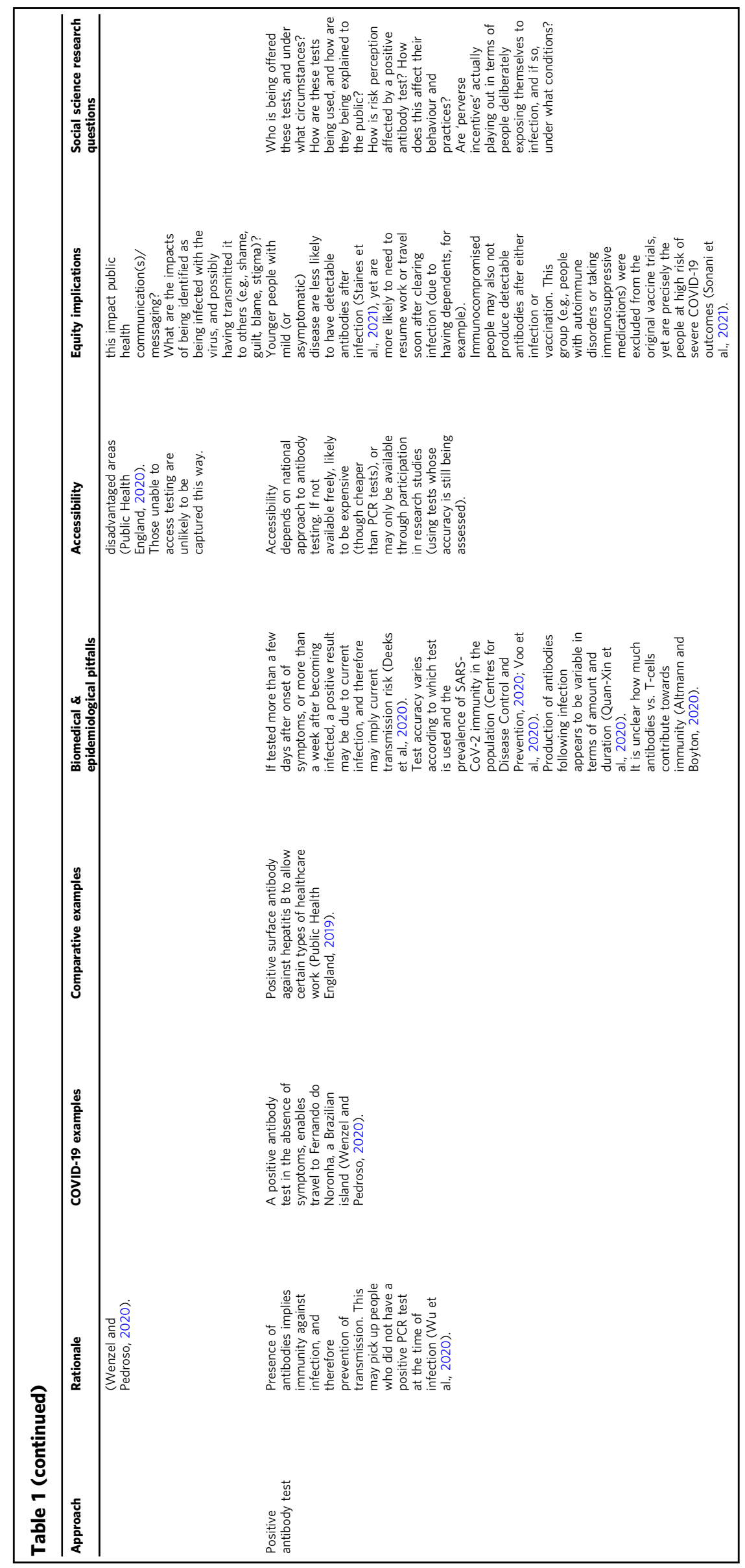


However, other precedents and models should also inform our approaches to COVID-19, especially as we consider the range of policies being used or proposed. For instance, a recent negative swab PCR test prior to travel is either required for individuals to enter or may remove/reduce the duration of quarantine on arrival in many countries; however, this practice does not govern the process for acquiring that test, which might be prone to differential ease of access (Drury, 2020; 2020b). Drawing from previous examples in history, a system of physician-certified immunity was implemented in Gibraltar in 1828 for yellow fever, possibly the earliest surviving example of such passes (Sawchuk and Tripp, 2021). Almost a century later, the use of health certificates was adopted by various city health departments and the state of New York during the 1916 polio epidemic in the Northeastern United States. However, a health certificate from a private physician was not enough to certify a child 'free of infection,' on the basis that they could not be trusted to put the good of the community ahead of their patients' convenience (Rogers, 1986). Even with an official health certificate in hand, New York children were therefore frequently refused entry to nearby towns or threatened with quarantines as long as four weeks (Rogers, 1986). In the current case, variations in COVID-19 restriction policies and testing requirements for travel have led to private providers meeting the demands for PCR tests, raising potential issues around equity and access to testing. This profiteering extends to recent reports of selling fraudulent COVID-19 test results, which has led to suggestions that traditional paper-based certification is not trustworthy (Ellyatt, 2021; Werthmuller, 2021).

As another example of the pitfalls of such testing, mandatory intermittent testing of sex workers for HIV and other sexually transmitted infections has been argued to be an ineffective use of funds and to confer a false sense of security, in part due to the 'window periods' during which infections may go undetected (Jeffreys et al., 2012). Similar concerns have been raised in regards to SARS-Cov-2 PCR tests; COVID-19 has an average incubation ('window') period of around five days after exposure to the virus, during which PCR tests are usually negative (Böger et al., 2021). Furthermore, there is potential danger for the certificate itself to become the focus and goal of these clinical interactions, rather than the health of the individual or wider community (Jeffreys et al., 2012). This potentially increases the likelihood of fraud and may impact the ability to access testing for symptomatic individuals, due to unclear priorities for resource allocation (Jeffreys et al., 2012). For COVID-19, it may matter who does the testing and issues documentation, and if they are seen as impartial, reliable, and trustworthy. Further, profitable pre-travel testing in some contexts may lead to the diversion of private laboratory resources potentially away from local health priorities.

With various vaccines in the pipeline, and vaccination programmes already beginning in many countries, we must again learn from history to ensure equitable access to the immunity they provide and the associated documentation. During the 1913 smallpox epidemic in New Zealand, successful vaccination enabled Māori to obtain a certificate for exemption from travel restrictions. However, travel to a town or city for the vaccine itself was possible only with documentation of previous vaccination, which many Māori did not have, creating a catch-22 that further entrenched existing disparities (Day, 1998). Despite Māori being most at risk in this epidemic, they had the most difficulty obtaining vaccines, as European New Zealanders prioritised their own protection (Day, 1998). With COVID-19, establishing equitable allocation and access to approved vaccines is a challenge. The COVAX initiative relies on global solidarity to finance and distribute the needed vaccines (Herzog et al., 2021). However equitable access to COVID-19 vaccines for global populations requires not only fair allocation of the vaccine but also systems in place to produce and deploy affordable vaccines at scale as well as mechanisms to promote vaccine acceptance (Herzog et al., 2021; Wouters et al., 2021).

Immunity-mediated certification has been used historically, and will likely be used again in future epidemic or crises settings. In the development and implementation of national and international COVID-19 related documentation measures, we must consider diverse historical precedents for immunity-based privileges, current scientific knowledge around COVID-19 immunity and testing, and the local context and implications of these policies. COVID-19 related documentation is a space characterised by significant uncertainty. While immunity from previous infection and potential for transmission after inoculation with a vaccine remain unclear (Peiris and Leung, 2020), a focus on the presence or absence of the virus itself is a narrow way to define health and wellbeing. Further, human biology cannot be assumed to look and work the same way across populations, space, and time. Researchers, advisors, and policymakers must learn from diverse cases in order to produce health policies that can work for different people on the ground.

\section{The importance of context}

When considering contextual factors that shape and are shaped by COVID-19 related documentation in practice, social science perspectives, methods, and theory are particularly valuable. Calls for increased engagement with social science methods and theory in implementation science emphasise that: 'It is not enough to know if a health intervention is effective; it is also necessary to understand why the intervention works, how, for whom and in which contexts' (Ridde, 2016). In terms of COVID-19, the reception of introducing and implementing documentation policies is influenced by the societal norms and expectations in the local context. For example, Israel, a country with compulsory national identity card regulations was one of the first nations to introduce the Green Pass (2021i). Meanwhile, such documentation policies have been largely criticised by lawmakers and the public in Ireland, the United Kingdom, and the United Statesnations without compulsory identity cards (Allegretti, 2021). Furthermore, a recent study analysing religious opposition to vaccination in the UK and Israel highlights how politicising discourses of 'beliefs' and 'hesitancy' frame religion and culture as obstacles to the intervention, whilst often obscuring and delegitimising the situated, structural, and wider contextual issues that crucially inform individuals' decisions and concerns about biomedical technology, its production, and how it is governed (Kasstan, 2021).

There are many different social science models and understandings of context, yet a key part of many of these is an appreciation of complexity and interaction of dynamic multi-level processes (Greenhalgh et al., 2017; May and Finch, 2009). Social science literature on implementation, discussing how health policies and guidelines unfold and are done in practice, highlights that this is not a straightforward undertaking that happens the same way everywhere for everyone (Greenhalgh et al., 2017; May and Finch, 2009; Ridde, 2016; Van Belle et al., 2017). However, more positivist accounts discuss 'following' or 'adhering' to health policies or guidelines, implying a linear process echoing the logic of determinism (Durlak and Dupre, 2008; Fischer et al., 2016). These accounts frame contextual realities through the lens of 'barriers' and 'facilitators' to effective implementation-rather than incorporating these considerations into policy and guideline development to better accommodate and reflect them.

Ethical and biomedical lenses have dominated discussions of COVID-19 related documentation, focusing on universal principles that should guide implementation (or not) (Brown et al., 
2020; Kofler and Baylis, 2020; Voo et al., 2020). Here, some of the social determinants of health are considered in questions of equity, stigma, and access. While these perspectives are essential, they are incomplete. They should also be complemented by further social science research into local realities and experiences that reveal how such policies become situated in lived context for individuals and whole groups, as illustrated by the historical examples above. A recent rapid review of public attitudes and behavioural responses towards COVID-status certification found that their conclusions about people's underlying reasoning were limited by the quality and quantity of the published studies, with high income countries overrepresented and most studies lacking demographic measures (Drury et al., 2021). The authors also note that these attitudes are likely to change over time, so studies conducted in 2020 based on hypothetical scenarios are likely to differ in their findings from those conducted now (Drury et al., 2021). We need this information to better understand and contextualise potential benefits and harm, and support necessary local adaptations.

The translation of science into policy and practice is similarly not a-contextual, as 'evidence does not form guidelines on its own' (Atkins et al., 2013). From the makeup and interactions of committee members, to the interaction of different policymaking sectors, to how evidence is considered, biomedical or scientific evidence should not be the only kind of evidence upon which these policies are based. We know that the success of [public health] interventions depends on local feasibility, acceptability, and fit with context-and hence on informed, shared decisionmaking with and by local communities' (Greenhalgh et al., 2014). Equally, a diversity of voices should feature in policy development processes, as well as in the implementation and communication of new policies, representing a diversity of experiences, interests, and priorities.

Bringing these local priorities and perceptions to the table is imperative. While economic and social considerations have featured in COVID-19 related documentation discussions over the last year (World Health Organization, 2020b; Das, 1999; Phelan, $2020 ; 2020 \mathrm{c}$ ), one of the less explored questions is how the intense focus on COVID-19 is perceived and experienced in different settings. These differences in priorities affect the implementation of any policy or health intervention (Yarborough et al., 2013). The polio eradication programme in Nigeria, for example, highlights the frustration of local people who saw public health priorities not reflecting their own (but those of wealthier others), as resources were directed to polio over basic healthcare and other diseases that impacted them more (Maryam, 2007).

\section{Moving forward}

Immunity-based documentation is already being implemented in various countries to various extents, with Israel's Green Pass regulating entry to public spaces, Air New Zealand's trial of the Travel Pass mobile app which stores health information such as COVID-19 test results and vaccination status in March 2021, and the more recent rollout of the EU Digital Certificate in July 2021 (Holmes and Kierszenbaum, 2021; 2021a; 2021c). These policies have been incorporated to various extents in different countriesfrom regulating domestic or international travel to restricting entry to large events and public spaces. The public reception to these policies has been mixed-leading to increased vaccination rates in Italy and France as well as protests in France and Canada (Hart, 2021; Jonas, 2021). While it is too early to comprehensively understand the implications of these policies, collecting data on these experiences is helpful in not only providing feedback to adjust policies and their implementation, but to also mitigate any harms that may arise in relative real-time. The effects of these measures and challenges with varying implementation will be felt differently across communities, populations, and countries potentially for years to come. These measures will become precedents for future policies, and will form the infrastructure for further public and global health systems. The perceived success of such measures will be determined by who you ask, when you ask them, and where they are. As such, these measures should not be uncritically transplanted from one context to another.

In prioritising a 'return to normalcy,' various countries have introduced policies for immunity passports that raise concerns about inequity by favouring more privileged populations. For example, when COVID-19 restrictions in Canada were announced at the end of 2020, the Immigration Minister exempted over 1700 athletes and business travellers from quarantine requirements (Harris, 2020). What does all of this reveal about the politics of life, and which lives-and which livelihoodsare valued? Studying these phenomena can add meaningfully to social science theory, which can and should feed back into the development of these policies, in order-rather than to 'return to normal'- to challenge the status quo and attending inequities, and better inform short- and longer-term public health responses. The experience gleaned from both diverse historical precedents and current social science research on the ongoing regulations to limit disease spread can broaden understandings of longer-term impacts and inform future effective and context-appropriate health policy and action.

\section{Ethical statement}

This study did not involve any human subjects and therefore was not subject to an ethical review process.

Received: 12 March 2021; Accepted: 6 September 2021; Published online: 27 September 2021

\section{References}

2020a. El Salvador to give immunity passports to those recovered from Covid Available: https://www.dpa-international.com/topic/el-salvador-giveimmunity-passports-recovered-covid-urn $\% 3$ Anewsml\%3Adpa.com $\%$ 3A20090101\%3A200810-99-116732.

2020b. India coronavirus: How do quarantine rules differ in major cities? $B B C$ News [Online]. Available: https://www.bbc.com/news/world-asia-india53218018.

2020c. Live Seminar COVID-19: Immunity Passports: Inevitable? Ethical?: The Global Health Network.

2021a. Air NZ to trial digital health passport app. RNZ [Online]. Available: https:// www.rnz.co.nz/news/national/436921/air-nz-to-trial-digital-health-passportapp [Accessed 22 Feb 2021].

2021b. Coronavirus (COVID-19) travel restrictions. Get Your Guide.

2021c. EU Digital COVID Certificate [Online]. European Commision. Available: https://ec.europa.eu/info/live-work-travel-eu/coronavirus-response/safecovid-19-vaccines-europeans/eu-digital-covid-certificate_en [Accessed].

2021d. France Requires Tourists to Hold Vaccination Passport to Access Certain Activities \& Services. Available: https://www.schengenvisainfo.com/news/ france-requires-tourists-to-hold-vaccination-passport-to-access-certainactivities-services/.

2021e. Freedom of Information request about lateral flow tests and COVID-19 vaccines (FOI 21/231). In: AGENCY, M. H. P. R. (ed.). London.

2021h. Travellers Vaccinated With Russian, Chinese \& Indian Vaccines May Be Unable to Enter Majority of EU Countries. Available: https:// www.schengenvisainfo.com/news/travellers-vaccinated-with-russian-chineseindian-vaccines-may-be-unable-to-enter-majority-of-eu-countries/.

2021i. What is a Green Pass? [Online]. Ministry of Health. Available: https:// corona.health.gov.il/en/directives/green-pass-info/ [Accessed].

Allegretti A (2021) Vaccine passports likely to be dropped as aid to lifting restrictions in England. The Guardian [Online]. Available: https:// www.theguardian.com/world/2021/may/31/uk-vaccine-passports-droppedlifting-restictions-theatres.

Altmann DM, Boyton RJ (2020) SARS-CoV-2 T cell immunity: specificity, function, durability, and role in protection. Sci Immunol, 5(49): eabd6160 
Atkins L, Smith JA, Kelly MP, Michie S (2013) The process of developing evidencebased guidance in medicine and public health: a qualitative study of views from the inside. Implement Sci 8:1-12

Böger B, Fachi MM, Vilhena RO, Cobre AF, Tonin FS, Pontarolo R (2021) Systematic review with meta-analysis of the accuracy of diagnostic tests for COVID-19. Am J Infect Cont 49:21-29

Borana R (2021) EU's 'Green Pass' plan leaves out covishield, serum didn't apply for approval. Available: https://science.thewire.in/health/eus-vaccinepassport-programme-includes-az-shot-but-not-covishield/

Bosch-Capblanch X, Zuske M-K, auer C (2017) Research on subgroups is not research on equity attributes: evidence from an overview of systematic reviews on vaccination. Int. J. Equity Health 16:95

Brown RC, Kelly D, Wilkinson D, Savulescu J (2020) The scientific and ethical feasibility of immunity passports. Lancet Infect Dis, 21(3), e58-e63

Callaway E (2021) Fast-spreading COVID variant can elude immune responses. Nature, 589(7843): 500-501

Centers for Disease Control and Prevention (2020) Interim Guidelines for COVID-19 Antibody Testing [Online]. Centers for Disease Control and Prevention. Available: https://www.cdc.gov/coronavirus/2019-ncov/lab/resources/antibody-testsguidelines.html [Accessed]

Centers for Disease Control and Prevention (2021) Using Antigen Tests [Online]. Centers for Disease Control and Prevention. Available: https://www.cdc.gov/ coronavirus/2019-ncov/lab/resources/antigen-tests-guidelines.html\#generalguidance [Accessed]

Chen LH, Wilson ME (2020) Yellow fever control: current epidemiology and vaccination strategies. Trop Dis Travel Med Vaccine 6:1-10

Crozier A, Rajan S, Buchan I, Mckee M (2021) Put to the test: use of rapid testing technologies for covid-19. BMJ 372:n208

Das V (1999) Public good, ethics, and everyday life: beyond the boundaries of bioethics. Daedalus 128:99-133

Day AS (1998) "The Maori Malady": The 1913 Smallpox Epidemic and Its Nineteenth Century Background. University of Auckland

Deeks JJ, Dinnes J, Takwoingi Y, Davenport C, Spijker R, Taylor-Phillips S, Adriano A, Beese S, Dretzke J, di Ruffano LF (2020) Antibody tests for identification of current and past infection with SARS-CoV-2. Coch Database Syst Rev

Dobler CC, Fox GJ, Douglas P, Viney KA, Khan FA, Temesgen Z, Marais BJ (2018). Screening for tuberculosis in migrants and visitors from highincidence settings: present and future perspectives. Eur Resp J, 52(1): 1800591

Drury C (2020) Denmark launches coronavirus passports. The Independent [Online]. Available: https://www.independent.co.uk/news/world/europe/ denmark-coronavirus-passport-travel-covid-19-a9609801.html

Drury J, Mao G, John A, Kamal A, Rubin GJ, Stott C, Vandrevala T, Marteau TM (2021) Behavioural responses to Covid-19 health certification: a rapid review. BMC Public Health, 21:1205

Durlak JA, Dupre EP (2008) Implementation matters: a review of research on the influence of implementation on program outcomes and the factors affecting implementation. Am J Commun Psychol 41:327-350

Ellyatt $\mathrm{H}$ (2021) Criminals are selling fake Covid test results as they look to profit from travel restrictions. CNBC, 1 Feb 2021

Ferhani A, Rushton S (2020) The International Health Regulations, COVID-19, and bordering practices: who gets in, what gets out, and who gets rescued? Contemp Secur Policy 41:458-477

Fischer F, Lange K, Klose K, Greiner W, Kraemer A (2016) Barriers and strategies in guideline implementation - a scoping review. Healthcare. Multidisciplinary Digital Publishing Institute, 36

Galea I (2021) Rapid COVID-19 tests could become workplace norm this fall. The Globe And Mail [Online]. Available: https://www.theglobeandmail.com/ business/article-rapid-covid-19-tests-could-become-workplace-norm-thisfall/?utm_source $=$ Shared + Article + Sent + to + User\&utm medium $=\mathrm{E}-$ mail:+Newsletters $+/+$ E-Blasts $+/+$ etc.\&utm_campaign $=$ Shared + Web + Article+Links

Gandhi M, Yokoe DS, Havlir DV (2020) Asymptomatic transmission, the Achilles' heel of current strategies to control COVID-19. Mass Medical Soc, (382)22: 2158-2160

Gostin LO, Cohen IG, Shaw J (2021) Digital health passes in the age of COVID-19: are "Vaccine Passports" lawful and ethical? JAMA 325:1933-1934

Greenhalgh T, Howick J, Maskrey N (2014) Evidence based medicine: a movement in crisis? BMJ: Br Med J 348:g3725

Greenhalgh T, Knight M, Buxton M, Husain L (2020) Management of post-acute covid-19 in primary care. BMJ, 370:m3026

Greenhalgh T, Wherton J, Papoutsi C, Lynch J, Hughes G, Hinder S, Fahy N, Procter $\mathrm{R}$, Shaw S (2017) Beyond adoption: a new framework for theorizing and evaluating nonadoption, abandonment, and challenges to the scale-up, spread, and sustainability of health and care technologies. J Med Intern Res 19:e367

Grover N, Allegretti A (2021) Rapid Covid tests used in mass UK programme get scathing US report. The Guardian [Online]. Available: https:// www.theguardian.com/world/2021/jun/11/us-health-agency-gives-innovalateral-flow-covid-tests-scathing-review
Harris S (2020) Ottawa granted 1,700 special quarantine exemptions to sports leagues and business travellers. Available: http://www.cbc.ca/news/business/ federal-government-quarantine-exemptions-travellers-1.5837629\#: :text= Sports\%20gave\%20'Canadians\%20some\%20'normalcy,entered\%20Canada\% 20 for\%20training\%20only

Hart R (2021) Vaccine passports spur explosion in vaccinations-and protests-as Europe cracks down on vaccine holdouts. Forbes [Online]. Available: https:// www.forbes.com/sites/roberthart/2021/07/27/explosion-in-vaccinations-andprotests-follow-health-pass-announcements-as-europe-cracks-down-onvaccine-holdouts/?sh=6243df14136b

Herzog LM, Norheim OF, Emanuel EJ, Mccoy MS (2021) Covax must go beyond proportional allocation of covid vaccines to ensure fair and equitable access. BMJ 372:m4853

Holmes O, Kierszenbaum Q (2021) Green pass: how are Covid vaccine passports working for Israel? The Guardian [Online]. Available: https:// www.theguardian.com/world/2021/feb/28/green-pass-how-are-vaccinepassports-working-in-israel

Jeffreys E, Fawkes J, Stardust Z (2012) Mandatory testing for HIV and sexually transmissible infections among sex workers in Australia: A barrier to HIV and STI prevention. World J AIDS 2:203

Jonas S (2021) Large crowd marches in Montreal to protest against Quebec's vaccination passport. CBC [Online]. Available: https://www.cbc.ca/news/ canada/montreal/protest-against-quebec-s-vaccination-passport-1.6141269

Kahn R, Rid A, Smith PG, Eyal N, Lipsitch M (2018) Choices in vaccine trial design in epidemics of emerging infections. PLoS Med 15:e1002632

Kasstan B (2021) "If a rabbi did say 'you have to vaccinate,' we wouldn't": Unveiling the secular logics of religious exemption and opposition to vaccination. Soc Sci Med 280:114052

Kofler N, Baylis F (2020) Examining 'immunity passports' from an ethics perspective-ten reasons why they are bad idea. Eur J Public Health, 30:ckaa165. 498

Lawless J (2021) UK to push at G-7 for global standard on 'vaccine passports' Available: https://apnews.com/article/travel-boris-johnson-londoncoronavirus-pandemic-2b37020c9621d9ec8ae042ba0abae019

López Seguí F, Navarrete Duran JM, Tuldrà A, Sarquella M, Revollo B, Llibre JM, Ara Del Rey J, Estrada Cuxart O, Paredes Deirós R, Hernández Guillamet G, Clotet Sala B, Vidal Alabaall J, Such Faro P (2021) Impact of mass workplace COVID-19 rapid testing on health and healthcare resource savings. Int Environ Res Public Health 18:7129

Mahase E (2020) Covid-19: Where are we on immunity and vaccines? Br Med J Publ Group

Maryam Y (2007) Polio vaccines: "No thank you!" barriers to polio eradication in northern Nigeria. Afr Affai 106:185-204

May C, Finch T (2009) Implementing, embedding, and integrating practices: an outline of normalization process theory. Sociology 43:535-554

Mills P (2020) Background discussion paper COVID-19 antibody testing and 'immunity certification': a discussion paper. Nuffield Council on Bioethics

Nichter M, Hedges K, Cartwright E (2020) Call to Action: Influence of Medical Anthropology for COVID-19 Response [Online]. Available: http:// arhe.medanthro.net/call-to-action/ [Accessed]

NSW Health Pathology and Office of the Chief Health Officer (2020) COVID-19 testing prioritisation [Online]. NSW Government. Available: https:// www.health.nsw.gov.au/Infectious/covid-19/communities-of-practice/Pages/ testing-prioritisation.aspx [Accessed]

Osama T, Razai MS, Majeed A (2021) Covid-19 vaccine passports: access, equity, and ethics. BMJ 373:n861

Peiris M, Leung GM (2020) What can we expect from first-generation COVID-19 vaccines? Lancet 396:1467-1469

Persad G, Emanuel EJ (2020) The Ethics of COVID-19 Immunity-Based Licenses ("Immunity Passports"). JAMA, 323(22): 2241-2242

Phelan AL (2020) COVID-19 immunity passports and vaccination certificates: scientific, equitable, and legal challenges. Lancet, 395(10237): 1595-1598

Phillips T (2020) Brazil's island idyll reopens to tourists -as long as they have had Covid-19. The Guardian [Online]. Available: https://www.theguardian.com/ world/2020/aug/30/brazil-island-fernando-de-noronha-reopens-touristscovid-19?CMP=Share_iOSApp_Other

Picard A (2020) Focusing on 'immunity passports' could distract us from the real goal. Available: https://www.theglobeandmail.com/opinion/article-focusingon-immunity-passports-could-distract-us-from-the-real-goal/

Public Health England (2019) Integrated guidance on health clearance of healthcare workers and the management of healthcare workers living with bloodborne viruses (hepatitis B, hepatitis C and HIV). Public Health England

Public Health England (2020) Disparities in the risk and outcomes of COVID-19. Public Health England

Quan-Xin L, Xiao-Jun T, Qiu-Lin S, Qin L, Hai-Jun D, Jun Y, Jie-Li H, Wei X, Yong Z, Fa-Jin L (2020) Clinical and immunological assessment of asymptomatic SARS-CoV-2 infections. Nat Med, 26(8): 1200-1204 
Ridde V (2016) Need for more and better implementation science in global health. BMJ Global Health, (1): e000115

Rogers N (1986). Screen the baby, swat the fly: polio in the Northeastern United States, 1916 (Epidemics, Urban)

Sawchuk LA, Tripp L (2021) Managing an epidemic in imperfect times: encampment and immunity passes in 19th century Gibraltar. BMJ Glob Health 6:e006713

Smout A (2021) Britain extends approval for rapid COVID test after U.S. rebuke. Reuters [Online]. Available: https://www.reuters.com/business/healthcarepharmaceuticals/britain-extends-approval-rapid-covid-test-after-us-rebuke2021-06-17/.

Sonani B, Aslam F, Goyal A, Patel J, Bansal P (2021) COVID-19 vaccination in immunocompromised patients. Clin Rheumatol 40:797-798

Staff T (2021) Ministers okay return of Green Pass; plan to ban travel to UK, Cyprus, Turkey. The Times of Israel [Online]

Staines HM, Kirwan DE, Clark DJ, Adams ER, Augustin Y, Byrne RL, Cocozza M, Cubas-Atienzar AI, Cuevas LE, Cusinato M (2021) IgG Seroconversion and Pathophysiology in Severe Acute Respiratory Syndrome Coronavirus 2 Infection. Emerg Infect Dis 27:85

The Lancet Microbe (2021) Vaccine certificates: does the end justify the means? Lancet Microb 2:e130-e130

Van Belle S, Van De Pas R, Marchal B (2017) Towards an agenda for implementation science in global health: there is nothing more practical than good (social science) theories. BMJ Glob Health, 2(2): e000181

Voo TC, Clapham H, Tam C (2020) Ethical Implementation of 'Immunity Passports' during the COVID-19 Pandemic. Available at SSRN: https://ssrn.com/ abstract $=3571830$

Voo TC, Reis AA, Thomé B, Ho CW, Tam CC, Kelly-Cirino C, Emanuel E, Beca JP, Littler K, Smith MJ (2021) Immunity certification for COVID-19: ethical considerations. Bull World Health Organ 99:155

Wamsley L (2021) The Olympics Are Really Happening. For Athletes, That Means A Huge Number Of Rules. NPR [Online]. Available: https://www.npr.org/ 2021/06/09/1004765190/the-olympics-are-really-happening-for-athletesthat-means-a-huge-number-of-rules

Wenzel F, Pedroso R (2020) Paradise islands reopen only to visitors who've had Covid-19. CNN [Online]. Available: https://edition.cnn.com/travel/article/ fernando-de-noronha-brazil-reopens-covid-19/index.html

Werthmuller D (2021) New Zealand warned to be alert at the border after spike in fake Covid-19 test results overseas. 1 News, 3 Feb 2021

Wiersinga WJ, Rhodes A, Cheng AC, Peacock SJ, Prescott HC (2020) Pathophysiology, transmission, diagnosis, and treatment of coronavirus disease 2019 (COVID-19): a review. JAMA, 324(8): 782-793

World Health Organization (2015) List of countries, territories and areas. Yellow fever vaccination requirements and recommendations; malaria situation; and other vaccination requirements. WHO, Geneva, p. 2015

World Health Organization (2020a). COVAX, the ACT-Accelerator vaccines pillar. World Health Organization

World Health Organization (2020b) "Immunity passports" in the context of COVID-19: scientific brief, 24 April 2020. World Health Organization

World Health Organization. (2020c) Transmission of SARS-CoV-2: implications for infection prevention precautions. World Health Organization

World Health Organization. (2021) Interim position paper: considerations regarding proof of COVID-19 vaccination for international travellers [Online]. Available: https://www.who.int/news-room/articles-detail/interimposition-paper-considerations-regarding-proof-of-covid-19-vaccination-forinternational-travellers [Accessed]

Wouters OJ, Shadlen KC, Salcher-Konrad M, Pollard AJ, Larson HJ, Teerawattananon Y \& Jit M (2021) Challenges in ensuring global access to COVID-19 vaccines: production, affordability, allocation, and deployment. Lancet, 397(10278): 1023-1034
Wu J, Liu X, Zhou D, Qiu G, Dai M, Yang Q, Pan Z, Zhou N, Wu P (2020) Identification of RT-PCR-negative asymptomatic COVID-19 patients via serological testing. Front Public Health 8:267

Yarborough M, Edwards K, Espinoza P, Geller G, Sarwal A, Sharp R, Spicer P (2013) Relationships hold the key to trustworthy and productive translational science: recommendations for expanding community engagement in biomedical research. Clin Transl Sci 6:310-313

\section{Acknowledgements}

The authors of this paper did not receive any payment or reward of any kind for writing this article. Funding for the Open Access publication fees of this article has been provided by the University of Auckland's School of Social Sciences PBRF Allocation Fund. The corresponding author had access to all the data presented in the study and had final responsibility for the decision to submit for publication.

\section{Author contributions}

$\mathrm{SD}, \mathrm{CP}, \mathrm{BS}$, and $\mathrm{HB}$ provided background research and contributed to drafting the initial version of this manuscript. NG and TS provided edits and feedback. All authors revised the manuscript before submission.

\section{Competing interests}

None of the authors have any known conflicts of interest to declare in respect of COVID19 immunity documentation. CP is a Postdoctoral Researcher at the University of Oxford, and her time is funded by the UKRI/NIHR 2019-nCoV Rapid Response Call (Grant No. NIHR200907). BS and TS are supported the National Institute for Health Research (NIHR) Global Health Research Group on Brain Infections at the University of Liverpool (No. 17/63/110) as well as the NIHR Health Protection Research Unit in Emerging and Zoonotic Infections (Grant Nos. IS-HPU-1112-10117 and NIHR200907). NG is part-funded by RECOVER, under the European Commission's Horizon 2020 research and innovation programme grant agreement 101003589. The views expressed are not necessarily those of the NHS, the NIHR, the Department of Health and Social Care, or PHE

\section{Additional information}

Correspondence and requests for materials should be addressed to Sara Dada.

Reprints and permission information is available at http://www.nature.com/reprints

Publisher's note Springer Nature remains neutral with regard to jurisdictional claims in published maps and institutional affiliations.

Open Access This article is licensed under a Creative Commons Attribution 4.0 International License, which permits use, sharing, adaptation, distribution and reproduction in any medium or format, as long as you give appropriate credit to the original author(s) and the source, provide a link to the Creative Commons license, and indicate if changes were made. The images or other third party material in this article are included in the article's Creative Commons license, unless indicated otherwise in a credit line to the material. If material is not included in the article's Creative Commons license and your intended use is not permitted by statutory regulation or exceeds the permitted use, you will need to obtain permission directly from the copyright holder. To view a copy of this license, visit http://creativecommons.org/ licenses/by/4.0/.

(C) The Author(s) 2021 